

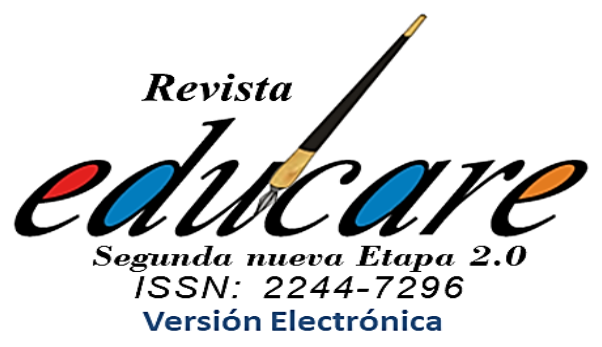

\section{CONCEPCIÓN DEL TALENTO DESDE UNA VISIÓN INTEGRADORA}

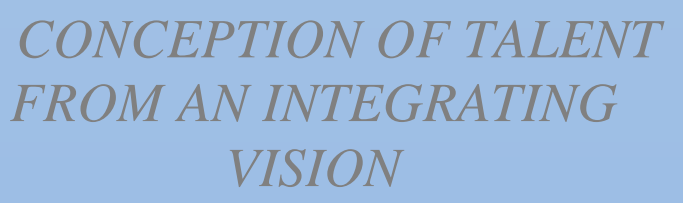

\section{Resumen}

El Talento se define como el alto desenvolvimiento que tiene un individuo en una o más áreas de desempeño humano, lo distingue de otro según sean sus potencialidades. Este término conlleva a la consideración de diversos aspectos en atención a todas aquellas aptitudes que manifiesta la persona. Ante lo dicho se presenta una indagación cualitativa -, que busca descubrir e interpretar ideas y reflexiones en relación al tema talento desde una visión integradora, por lo que se realiza una revisión exhaustiva que deja ver la apertura de pensamiento desde el acompañamiento de diversos aliados teóricos, como fuentes de información. Sus escritos físicos o virtuales son las unidades de análisis que permiten la visualización del talento desde una concepción más actual e integradora. Luego de la exploración investigativa se logra una apertura que vislumbra las ideas concebidas en relación al tema de estudio.

Palabras claves: Talento; actualidad; visión integradora.

\section{Abstract}

Talent is defined as the high development that an individual has in one or more areas of human performance. It distinguishes him from another according to his potentialities. This term leads to the consideration of various aspects in attention to all those aptitudes that the person manifests. Given what has been said, a qualitative inquiry, which seeks to discover and interpret ideas and reflections in relation to the subject of talent from an integrative vision, for which an exhaustive review is carried out that reveals the opening of thought from the accompaniment of various theoretical allies, as sources of information. Their physical or virtual writings are the units of analysis that allow visualizing talent from a more current and integrative conception. After the investigative exploration, an opening is achieved that glimpses the ideas conceived concerning the subject of study.

Keywords: Talent; current affairs; inclusive visión 


\section{Introducción}

Cada persona tiene una característica que resalta a la vista de todos y esta le hace sobresalir en un grupo por las demostraciones únicas que realiza. Esta capacidad que demuestra un sujeto permite que se destaque de manera significativa en lo que efectúa, por lo que se considera un rasgo o parte de sí y se entiende como la aptitud que como ser humano posee. Ese talento natural, que le ha acompañado desde toda su vida o que ha aflorado o sido descubierto durante algún instante de su existencia, si se reconoce y desarrolla, lleva al hombre o mujer a su crecimiento y le permite fusionar sus talentos al quehacer diario de la vida para alcanzar mejores niveles de desenvolvimiento.

Talento, en sentido amplio, es la palabra que engloba en esencia ciertas características de una persona y que le hacen desenvolverse de manera única en un contexto determinado $\mathrm{y}$, en muchos casos, es el canal por medio del cual los individuos se comunican, expresan a sus semejantes su vida interior, sus temores, alegrías, frustraciones, metas, propósitos de vida; para así dejar ver abiertamente todos aquellos aspectos que forman parte importante de su ser.

Al revisar diversas fuentes informativas vinculadas al tema, tales como: Lorenzo (2006), Betancourt y Valadez (2003), Zavala y Rodríguez (2004), entre otros; se encuentra una extensa gama de materiales que apuntan hacia el talento desde una visión psicométrica, innatista, conductual, visto desde una concepción de expresión de inteligencia o niveles de coeficiente intelectual (CI). En los escritos se explica al fenómeno como algo que solo algunos poseen, esa capacidad que sobrepasa todos los estándares y permite que se vea a la persona como un sujeto sobrenatural, un superdotado capaz de demostrar aptitudes que nadie más puede tener. En cada una de las indagaciones visualizadas se exaltan sus comportamientos especiales, por encima del ser como individuo a la par de otros quienes también demuestran potencialidades que le hacen ser diferentes por el simple hecho de tener humanidad, aun cuando las manifestaciones de sus talentos sean en una misma área de desenvolvimiento.

En este sentido, se concibe el talento como todas las manifestaciones individuales exteriorizadas de forma espontánea en el hacer cotidiano de una persona, y que pueden estar presentes desde su niñez o son descubiertos y desarrollados a través de las vivencias que se experimentan en diversos contextos y se reflejarán a través de cada habilidad, 
destreza, aptitud, o potencialidad que un individuo demuestre al accionar en un asunto determinado o en diversas actividades, en las cuales puede destacarse con actitud placentera por lo que realiza. A partir de esta idea, se da la búsqueda de variados aliados heurísticos que difieren o complementan el pensamiento expuesto y es aquí que se centra la indagación en el descubrir e interpretar las palabras de los autores con los cuales converso y cruzo pensamientos para alcanzar una visión integradora del talento, no vista desde los estándares clásicos, sino con mente abierta que considera que todos tenemos talento y lleva a la consolidación del término desde una visión más integradora.

Talento, en el contexto de esta revisión documental, será todo lo que se pueda expresar a través de acciones y destrezas para lo que se es bueno y que además se hace con alegría, porque permite sentir que se está ubicado en algo; ello deja claro el pensamiento de que el talento es aquello en lo que te destacas y te encanta hacer demostrándose de forma natural. Pueden existir personas con bajo rendimiento en algunas de sus actividades, pero siempre tendrán cierta habilidad o destreza que les ayudará a hacer bien otras cosas, en ocasiones los talentos están a la vista de todos y en otros casos están escondidos, pero siempre estarán dispuestos a ponerse en práctica cuando se lo proponga la persona.

La idea planteada anteriormente toma fuerza en lo dicho por Maxwell (2007), cuando expresa

No importa qué tan consciente seas de tus habilidades..., o si anteriormente hayas logrado el éxito. Tienes talento y tú puedes desarrollarlo (p. 7). El talento puede capacitar a las personas para hacer cosas extraordinarias y debemos reconocer el talento de las personas y maravillarnos de sus logros (p. 4).

El autor declara firmemente que el talento que se posee permite al ser humano desarrollarse de manera plena, se deja atrás las concepciones primitivas que ven al talento solo desde la máxima inteligencia y se abre camino a nuevas ideas.

Ante este aspecto me alineo con las palabras de diferentes autores que tienen criterios variados dignos de ser revisados, profundizados para la lectura de todos. Conocer las opiniones o sentir de otros en cuanto a sus vivencias, nos permite llevar nuestros ojos y oídos a un intercambio de ideas, que dan cuenta de las cosmovisiones que cada sujeto aprehende para sí en la construcción de su subjetividad, reconstruidas con sus pares. Esta idea, permite un viaje al encuentro con otros, aliados que incursionan en diversas áreas 
heurísticas, para conocer las concepciones o visiones que estos tienen en torno al talento. Todo esto en la búsqueda del conocimiento constante que permite al individuo un amplio crecimiento y entendimiento de su contexto.

\section{Ubicación del Talento en la Historia}

El tema del talento (aunque no manejado con este término desde el inicio), según Osorio (2000), ha sido revisado por algunos estudiosos que consideraban que las personas talentosas debían ser quienes dirigieran los grupos sociales del momento. La autora, señala algunas proezas realizadas por figuras importantes como Platón en el siglo IV a.C; Soleiman, El Magnífico (siglo VI), quienes buscaban proteger y desarrollar las ciencias y las artes, a través de numerosos filósofos, convirtiéndoles en grandes poetas de la época, con el arduo deseo de preparar a un grupo selecto de personas, que se encargarían de las decisiones más importantes de la comunidad.

Salazar y Fernández (2016), comentan que la visualización del término talento, radica desde los tiempos de Confucio, Platón y Soleiman, quienes apoyaban la idea de los "niños precoces", término que fue utilizado a mediados del siglo XVIII hasta los inicios del siglo $\mathrm{XX}$, tiempo en el que se ubican algunas figuras resaltantes como Mozart, Galton, entre otros; ellos se destacaban en ciertos aspectos y sobresalían de la norma en comparación con el resto de los habitantes. Se hace necesario acotar, que, para el momento de las épocas señaladas, se buscaba la organización de una sociedad dirigida por los más destacados, eran preparados desde la infancia en las mejores escuelas, con la intención de que estos fueran los que tomaran la dirección del gobierno en su juventud, para demostrar sus habilidades y aptitudes ante el reto que se les exigía.

Para Zavala y Rodríguez (2004), entrado ya el siglo XX, surgen nuevos defensores, como: Bidet - Simon, M. Terman; los cuales se interesan en la profundización del tema de la inteligencia. Crean una serie de pruebas que miden la capacidad intelectual de cada individuo y así poder identificar a niños superdotados. Es a partir de estas investigaciones, cuando empiezan a realizarse las diferentes revisiones que llevarían luego a una identificación y conceptualización de lo que hoy se denomina talento.

Este gran paso dado desde lo científico, permite entender el funcionamiento cerebral de toda persona y se arraigó firmemente a las creencias individuales, lo que ha hecho difícil ver el talento desde otra visión, cada revisión que se hace del término, siempre lo ven desde 
que tan bien piensas, cognitivamente hablando, cualquier otra cosa que hagas no sirve, si no demuestras inteligencia, no encaja. Seguimos en la idea de Binet y Terman, aunque estemos en otros tiempos. Este pensamiento hace reflexionar ¿ha sido la inteligencia lo único importante al hablar de talento, en la continuidad histórica del talento?, entonces encuentro que hay cambios en relación con la forma de ver y asumir el talento de las personas.

Se da una transformación paradigmática entre los años 1960 y 1970 aproximadamente, cuando se produce una ruptura entre el término empleado con mayor fuerza hasta el momento para denominar a esta población, -súper o sobredotación-, y se pasa a definirlos como personas con Talento y así se humaniza la concepción que se tiene de los individuos.

Venezuela no escapa de estos cambios paradigmáticos y a través de sus leyes da apoyo gubernamental para la atención oportuna en el ámbito educativo. En este sentido, se ubica el último material legal dictado en el país que expone el recorrido histórico en relación al tema de estudio, se refiere al documento de conceptualización y política para el desarrollo del talento, de la modalidad de educación especial emanado por el Ministerio de Educación, Cultura y Deporte (1997), luego de esta fecha se encuentra un nuevo archivo del año 2016, que poco contempla información directa sobre el talento, por lo que, para el presente estudio se parte de lo expresado en el mencionado documento de 1997.

En este se explica que a mediados de los años 40 se promueven acciones filantrópicas que tratan de incitar un interés por el desarrollo del talento en busca de la valoración de las personas que demuestran habilidades en una o varias áreas del desenvolvimiento humano con la intención de dar más apertura en la sociedad. Pasaron muchos años y sucesos para que se pudiera iniciar un verdadero interés por el talento de las personas y hasta se puede decir, que continúa hoy en día esta ardua tarea.

Se han escuchado comentarios de algunas personas que expresan el deseo de sentir que su talento es visto por todos, que se tome en cuenta las habilidades demostradas en lo que hacen; esto trae una especie de bienestar que lleva al sujeto a experimentar que lo que es coincida con lo que hace. Estas palabras expresan un gran sentir que continúa moviendo la historia del talento, principalmente en Venezuela, por estas formas de pensar, sigue un grupo de personas en lucha por cambiar la idea del término talento. 
Lo comentado por ese grupo de la población, llama al texto a Maxwell (2007), quien señala que el talento impregna la cotidiana de una persona, y allí todo lo que realice toma valor al coincidir el ser con la acción, en una armonía especial que llena al individuo, "Cuando hago las cosas para las que fui diseñada, me siento realmente vivo" (p.43). Palabras que unidas a la expresión del párrafo anterior deja claro que el talento fusiona el sentir interno con la exteriorización y hacen de la persona un ser pleno que vive lo que hace.

En la década de los 80 y 90, se trató de implementar un proyecto a lo largo de todo el país, para la agrupación de la población en diferentes talleres que conllevaron a la reorganización del plan inicial, pero siempre con una visión monolítica, indiferentemente del nombre que se le diera a los proyectos de moda, solo se buscó el avance cognitivointelectual de los estudiantes que se trabajaron.

En la primera década del 2000, se intenta cambiar la forma de referirse al talento, pero aún continúa la creencia, en algunos casos, del aspecto cognitivo del término. Aunque la seguridad de que la postura intelectual persiste hasta nuestros días; considero que en la actualidad se ha tratado de cambiar esta concepción por una visión más holística e integral, apoyándonos en las teorías propuestas en la perspectiva social de Gardner (Regader, 2015).

\section{Concepciones del Talento}

Hablar de talento siempre hará mención a cada una de las habilidades, potencialidades y aptitudes que una persona tiene en un área determinada, permitiéndole destacarse en las actividades vinculadas con lo que ejecuta. La idea de que el talento -como cualidad particular en la que el individuo sobresale y, por decirlo de algún modo, fluye sin problemas- es una fortaleza que le permite desenvolverse en el mundo, el talento es estar todos en un mismo nivel nadie por encima o por debajo, como para tratarnos de forma especial. Todos somos talentosos en tanto se tiene algún talento para algo particular en mayor o menor grado.

En este sentido, Lorenzo (2006), señala que el talento "es aquella capacidad que se presenta como significativa en cualquier persona y que la hace sobresalir dentro de su grupo" (p.89). Este puede manifestarse en un aspecto o ser combinado entre varios de ellos (habilidades intelectuales, sobresalir en alguna área, liderazgo, capacidades motoras, habilidades en las artes y potencialidades creativas o productivas). 
El talento, en cuanto a la visión filosófica-psicológica tiene cabida en lo propuesto por la corriente humanista social, que propone una postura antropocéntrica, que ve al ser humano como el centro de todo y brinda beneficios a la sociedad en la cual convive. La persona bajo esta perspectiva busca la autorrealización, autoconciencia y la toma de decisiones que le permitirán al sujeto considerarse a sí mismo de manera activa en la exteriorización de sus habilidades y potencialidades, en los distintos contextos en los cuales se desenvuelve (Malavassia-Calvo, 2017).

Se toma en cuenta las ideas humanistas de Carl Rogers, quien considera la concepción de persona desde la individualidad, de la creencia de ese hombre o mujer que manifiesta unas características personales que lo hacen distinguirse de los demás y que, a su vez, es un ser colectivo que forma parte de un grupo social; sus comportamientos, actitudes y manera de desenvolverse con sus iguales, le hacen ser merecedor de respeto y comprensión hacia su persona. “...no es fácil permitirse comprender a un individuo...En efecto, esto es algo que ocurre con escasa frecuencia...ser comprendido tiene un valor muy positivo" (Rogers, 2011, p. 32).

El talento es una representación propia de cada individuo, las habilidades que demuestran son distintas en uno y en otros, pero puede compartirse con los demás en un ambiente de tranquilidad y respeto. Esta idea hace ver que desde el humanismo se busca la consolidación de una persona consciente de sus potencialidades y que al mismo tiempo es comprendida por su entorno, lo que le permite compartir con otros su ser, en una convivencia cercana que les hace crecer juntos. Esta cercanía les será de ayuda para alcanzar con otros un estado de crecimiento óptimo (Malavassia-Calvo, 2017).

Dentro de esta postura se ha tratado de garantizar el acceso a una educación integral, el respeto a la diversidad en igualdad de condiciones y oportunidades, para que participen de manera activa y responsable en los cambios requeridos para el desarrollo del país. El pensamiento humanista social, restituye en el educando su verdadera cualidad esencial: la de ser persona. Por ello, considera al estudiante desde una concepción holística: como un ser en permanente crecimiento, único en sus características y en sus necesidades, constructor de su propia concepción del universo, necesariamente gregario en sus proyecciones e interacciones sociales, y ratificador de los valores intrínsecos de su propia existencia como individuo pensante. 
En este mismo sentido, y en consideración de los postulados vinculados con el humanismo social, se toma la idea de que todos tenemos aptitudes que podemos desarrollar durante las interacciones sociales que llevamos a cabo, estas habilidades en muchas ocasiones sirven de base para desenvolvernos en diferentes contextos con nuestros pares. Esta teoría comprensiva, parte de la subjetividad de los valores, creencias, emociones; presentes de forma continua en las personas, haciéndolos únicos - distintos a unos de otros, a su vez destaca que las acciones que reproducen los sujetos, repercuten directamente sobre su entorno y este sobre el individuo, esto con un carácter recursivo entre ambos (Capo, 1986).

Lo planteado con anterioridad, se vincula con el talento cuando señala que todo ser humano tiene características particulares que le hacen diferenciarse de los demás, al igual que también puede llegar a expresar destrezas y habilidades que le distinguen de otros individuos, pero al mismo tiempo estas aptitudes que les diversifican, influyen sobre sus relaciones en los distintos contextos en los que hacen vida.

Para Vinueza y Castro (2018), los primeros rasgos del talento se presentan en la infancia, estos pueden ir configurándose durante la adolescencia o juventud, lo que, con una adecuada orientación y exploración, podrá definirse, desarrollarse acertadamente en la adultez. Este desarrollo dependerá en gran medida de las oportunidades que se le brinden para desarrollarse, de las relaciones que la persona pueda establecer con los padres, docentes, la comunidad y el medio ambiente. Esta afirmación es apoyada por Andreucci (2016), quien expone que el talento es dinámico, puede verse desarrollado en la medida que interacciona con otros entornos, como la educación y que estas habilidades pueden ser evidentes desde la infancia, potenciadas durante la juventud a través de las experiencias.

Estas ideas permiten asumir bajo esta filosofía, a un individuo con una integridad biopsico-social, con capacidades, potencialidades, necesidades, intereses y diferencias individuales que los convierten en seres únicos, distintos entre ellos, por lo que, exigen una atención educativa integral que les permita maximizar el desarrollo de sus propios potenciales, cualquiera que estos sean, para lograr el afianzamiento de sus aptitudes. Se concibe a la persona con un pensamiento integrador, por lo que se cree en la formación de un ser que pueda llegar al reconocimiento de sus habilidades, con el apoyo social y la valoración intrínseca que cada individuo tenga. Un ser capaz de trabajar para sí mismo, 
pero con una visión social, que asimila sus potencialidades como palancas que mueven al mundo.

\section{El Talento: Cualidad Inherente al Ser Humano}

Los talentos vienen marcados desde la infancia, como comenta M. Materán (entrevista personal 20 de septiembre de 2020), quien relata: "yo desde niña me destaco en el hablar en público, pero digo que ha sido innato, soy muy extrovertida y me encanta exponer, explicar. Tengo la idea de algún día prepararme como moderadora o locutora, sería buena en ese medio". En el discurso de la invitada se destacan dos aspectos importantes: por un lado, el carácter innato del talento y por otro su capacidad de autoreconocimiento con el consecuente agrado e intención de aprovecharlo a futuro para hacerlo parte de su acción profesional o laboral (ser locutora o moderadora).

Ambos aspectos se vinculan con las palabras de Velasco y Prieto (2012), quienes reconocen que "el talento es una cualidad inherente a las personas, evaluable, que permite destacar con comportamientos altamente eficaces, con elasticidad suficiente para adaptarse a las exigencias cambiantes del entorno" (p. 1); esta inherencia a las personas puede estar relacionada y explica de algún modo el que algunos comportamientos, habilidades, destrezas, como la buena expresión lingüística de Materán, sean innatos. Su reconocimiento es lo que permitirá hacer consciente al portador del talento de que éste le permitirá destacarse o sencillamente ser bueno para disfrutar de algo que le es propio en diferentes contextos y exigencias.

En lo dicho anteriormente, resalta la idea de que el talento de cada persona siempre estará presente con ella, solo que si lo dejamos de practicar puede llegar a deteriorarse o hasta olvidarse y será más difícil recordarlo luego. Así como lo expresa L. Güere (conversación telefónica, 05 de enero de 2021), "Lo que no se practica se puede olvidar...hay que practicar mucho más luego para retomarlo de nuevo". Al hablar de las aptitudes que durante toda la vida puede demostrar un individuo, queda claro que estas deben ser ejercitadas para recordarlas y puedan perdurar en el tiempo.

En este sentido, Hernández (2018), comenta que las habilidades personales se pueden expresar de manera consecutiva o se pueden desarrollar en el tiempo durante el compartir de experiencia enriquecedoras con otros. El talento se manifestará en la medida que lo trabajamos, mientras más lo cultivas, más fácil será expresarlos. 


\section{Talento: Una Esencia Individual}

Cada ser humano en su naturaleza es única e irrepetible. Son varios los comentarios y escritos que nos expresan tal afirmación. Rogers (2011), señala que los individuos son seres que pueden ser definidos desde sus propias interacciones con su entorno y la manera como se desenvuelve en este, se dará de forma individual, que no podrá ser copiada por alguien más.

La idea de que somos individuales en cuanto a nuestra esencia personal, nos permite interpretar que cada uno demuestra sus propios caracteres, personalidad, sentimientos, pensamientos, actitudes y talentos; este señalamiento toma fuerza en las palabras de Montaño et al. (2009), quienes hacen referencia a que cada ser humano manifiesta "un conjunto de cualidades propias de cada persona en particular" (p.5), es decir somos seres irrepetibles, sin copias.

La teoría humanista considerada expone que cada individuo tiene la potestad de comportarse según su criterio, en la que su visión subjetiva le diferencia de otros. En esta idea encaja el pensamiento de que, así como los variados aspectos que forman a la persona, le pertenecen únicamente a ella, también el talento será un atributo individual que aunque un grupo de personas manifiesten habilidades en una misma área, siempre habrá diversidad de talentos, según cada uno de los seres humano, en relación a su semejante.

En tal sentido, se develan, descuben y se interpretan las expresiones acerca del talento, que emergen de las revisiones documentales, las mismas conllevan a la elaboración de un cuadro categorizador en torno a la competencia particular puesta en práctica en ámbitos específicos, el talento como un sello significativo individual, el accionar desde el talento: una actividad valiosa en el dar y recibir, los poli-talento: uno o varios en un mismo ser y la idea de que todo el ser se expresa en el talento; tal como se observa en el cuadro 1:

\section{Cuadro 1}

Talento: Una Esencia Individual

\section{Aspecto descubierto}

- Competencia particular puesta en práctica en ámbitos específicos

\section{Idea poderosa}

El talento es único en cada persona y será expresado según la necesidad e interés del individuo, en los contextos en los cuales hace vida activa. 
- El talento es un sello significativo individual

- Accionar desde el talento: una actividad valiosa en el dar y recibir

- Poli-talento: Uno o varios en un mismo ser

- Todo el ser se expresa en el talento
Capacidad que se tiene para desarrollar potencialidades que le ayudan a relacionarse con el entorno, distinguiéndose en lo que hace, al manifestar su vida interior.

El talento no solo serán las habilidades o potencialidades que distinguen a un sujeto en un contexto determinado, sino que también aporta al individuo una expansión del enfoque personal, que le lleva a su progreso.

Variedad de aptitudes que los seres humanos emplean de modo natural para demostrar sus habilidades, que les distinguen en lo que hacen.

El cuerpo se convierte en un instrumento irremplazable de expresión humana, que permite ponerse en contacto con el medio y con los demás.

\section{Fuente: propia}

El talento como una competencia particular puesta en práctica en ámbitos específicos, tiene la idea de que existe distinción en el talento expresado por cada persona, y deja ver que todos somos diferentes, así como se valora la individualidad, también el talento será expresado de manera única. En este sentido, Rogers (2011), comenta que la individualidad de cada ser será reflejada en todo lo que realice y deja ver su interior cuando ejecuta sus acciones. Al leer lo escrito por el autor se puede ver claramente que el talento al igual que otros aspectos de las personas, son distintos en cada una, por lo que indiferentemente si el talento se expresa por un grupo en la misma área, este siempre es disímil en ellos, en todo momento habrá aspectos propios que le hacen ser particular de sus iguales.

Al hablar de habilidad según el Diccionario de la Real Academia Española (RAE) (2021), refiere a la "Capacidad, disposición, ... gracia y destreza que tiene una persona en ejecutar algo..., como bailar, montar a caballo, etc". (p. 1). Entonces al decir habilidad personal, se hace mención a cada una de las destrezas que son exteriorizadas de forma única por un individuo. Cuando se menciona el talento que una persona puede llegar a demostrar, se deja claro que esta potencialidad solo puede ser expresada por ella. Esta definición dada, deja ver que todos son distintos, aun en los talentos que se manifiestan y esto marcara una gran diferencia en la unicidad de cada sujeto, se distingue a los unos de los otros, aun cuando se interactúe en un mismo contexto social, por lo que el talento permite a cada humano ser único en cuanto a sus habilidades personales, sin menospreciar nunca lo que el otro es capaz de hacer. 
Dado que el talento es único en cada individuo, su exteriorización también podría darse en ciertos espacios; podemos demostrarlo en un ámbito específico, en el momento que se necesite, lo dicho se interpreta en lo escrito por Cabrera (2011), cuando señala que los contextos de interacción para la manifestación del talento personal, estarán definidos según sea la habilidad que se demuestre por el individuo, ante una situación que lo amerite.

Los comentarios anteriores dejan ver que la aparición de las potencialidades se da de acuerdo a la necesidad o interés que exista, para hacer uso del mismo en un contexto determinado. Idea que deja ver que el contexto para demostrar los talentos de cada persona, serán aquellos en los que los estudiantes se sientan identificados, y así puedan llegar a hacer de estos como lo indica Cabrera (2011) un contexto organizativo, para favorecer la reflexión sobre la experiencia y la construcción de nuevos saberes para transformar las capacidades individuales, de manera que pueda llegar a impactar sus vidas y las de quienes junto a ellos conviven.

En este sentido, Rodríguez et al. (2019), reflexionan sobre lo señalado por algunos autores y dejan ver que el talento "... se caracteriza por resultados altamente satisfactorios en una o varias áreas de conocimiento, las artes y/o el deporte...” (p. 164). Lo expresado por los autores, deja clara la visión de que el talento de una persona se convierte en un motor que permite que se destaquen y se sientan útiles. Asimismo, la evidencia final al presentar los talentos durante la cotidianidad individual deja un sabor de satisfacción sobre el sujeto que lo acciona, lo cual puede llegar a producir cambios significativos sobre esta. De igual manera, Gagné (2009), apunta que el talento designa el dominio destacado de capacidades sistemáticamente desarrolladas, en al menos un campo de la actividad humana.

Las líneas que preceden, enuncian el pensamiento de que los individuos viven experiencias, a través de las cuales pueden llegar a exteriorizar sus talentos en su cotidianidad y, al ser puestos en acción, dan oportunidades de destacarse de manera significativa en lo que se hace, por lo que la persona puede llegar a experimentar complacencia por su ejecución. Al hablar de significativo, en el tema del talento, será todo aquello que tiene un lugar muy importante en el interior de cada ser humano y le permite sentirse apto para vivenciar y aportar a cualquier situación, de la mejor manera posible (Maxwell, 2007). 
Accionar desde el talento: Una actividad valiosa en el dar y recibir presenta la idea de que el talento, no es un artículo de lujo del que puede llegar a presumir una persona, por el contrario, se concibe como un recurso que brinda oportunidades de desarrollo personal y profesional. La práctica consciente del talento individual, puede ser una palanca que brinda al ser humano ocasiones para alcanzar aprendizajes que enriquecen su existencia en diferentes sentidos.

Se habla de los momentos en los cuales un sujeto debe indagar para conocerse más, o para profundizar en áreas de su vida, en las que pudiera ser mejor cada día, su talento se convierte en apoyo que le orienta, da dirección y le impulsa más allá como lo expresa, con el cual se abren puertas de autoconocimiento y crecimiento. Esto hace ver que el talento no solo serán las habilidades o potencialidades que distinguen a un sujeto en un contexto determinado, sino que también aporta al individuo una expansión del enfoque personal, que le lleva a su progreso.

En este sentido Maxwell (2007), expone que el talento va de la mano con la preparación que decidiera llevar a cabo el ser humano, y que esta no significa tener un dominio de todo o poseer todas las respuestas, más por el contrario a través del talento se puede el individuo colocar a sí mismo en una posición, de mejoría intelectual, actitudinal, emocional y relacional. El precitado autor cree que "La preparación posiciona a las personas de manera correcta" (p. 54). Lo anterior deja ver que toda disposición al crecimiento, acompañado del talento que cada uno posee, brinda un mejor desarrollo intrínseco que se ve reflejado en la vida diaria de cada uno.

Del mismo modo, se concibe la idea de que durante estos procesos de aprendizaje que se cumplen, el talento da facilidad para aprender y enseñar algo, es decir recibes fortalezas que permiten que la preparación que realiza cada cual, se dé de manera desenvuelta e intencional, de forma recíproca: yo te enseño desde mis experiencias y aprendo desde tus vivencias.

Dado que lo que vivimos tiene gran valor y sentido, se puede ver que el talento que demuestro, exteriorizo o simplemente comparto con otros, en palabras de Rogers (2011), se convierte en una actividad valiosa, que tiene sentido para mí porque me deja algo nuevo y si esto le hace sentir así, efectivamente vale la pena. El autor cree que todo aprendizaje que 
se adquiere desde la experiencia es más fidedigno que la razón, por esto el talento facilita desde sus escritos el enseñar y aprender.

En cuanto a poli-talento: uno o varios en un mismo ser se refiere, diversos autores explican que el talento puede ser evidenciado en diferentes áreas del quehacer humano. Algunos de ellos van desde las consideraciones cognitiva, psicomotoras, espaciales, lingüísticas, lógico matemático, relacionales, simples, complejos, específicos, generales y pare de contar con respecto a las tipologías encontradas; unas con una visión psicométrica y otras desde lo social ambiental. Lo realmente importante para efecto del presente estudio, radica en lo interpretado desde la visión integradora.

L. Güere (conversación telefónica, 05 de enero de 2021), expone que "Hay varias formas de talento, yo toco el cuatro, mis amigas narran, cocinan, se expresan muy bien y así...", da la visión que la existencia de uno o varios talentos, quedará explicado según sean las cualidades que expresen los individuos. Para Teplov (1961), el talento será una manifestación de capacidades en la que los sujetos están dotados de manera distinta, que, aunque se expresan en un mismo tipo de actividades, cada individuo revela un talento que le diferencia.

Muchas son las formas en las que un grupo de personas exteriorizan lo que mejor sabe hacer, aquellas potencialidades con las cuales puede mostrar su mundo interior. Hablar de tipos de talentos se refiere a la variedad de aptitudes que los seres humanos emplean de modo natural para demostrar sus habilidades, que les distinguen en lo que hacen. Autores como Gagné (2009), plantean que la demostración del talento puede darse en lo académico, las artes, científico, técnico, deportivo, social y empresarial.

Unos tenemos talentos para una cosa y otros para otras y esto destaca la diversidad de potencialidades que demuestran los seres humanos. De tal manera que pensar en talento es pensar en variedad, hasta se puede creer que cada sujeto social es un ser talentoso, por lo que todos tenemos al menos una destreza que ejecutamos bien en nuestro día a día (Betancourt \& Valadez, 2012). Cuando se complementan varios talentos es maravilloso, ver a una misma persona con diferentes habilidades, que grandioso, se puede demostrar más de un talento, es decir en algún momento de su vida un sujeto podría llegar a declarar con su comportamiento que posee varios talentos que pudieran ser fusionados o no de acuerdo a 
las situaciones cotidianas a las cuales deba hacer frente. Y es allí donde Teplov (1961) habla de la polivalencia de los talentos

El talento es en esencia polivalente. No quiero decir con esto que todo sujeto talentoso en un dominio, deba ser obligatoriamente un hombre excepcional en lo demás, y que todo músico deba ser también pintor, poeta, actor o científico. Lo que cuenta no es el número de especialidades, sino la extensión,y el aspecto múltiple que revista su desarrollo. Una persona puede no tener sino una especialidad y ser muy diversa...(p. 45)

Ante esto se puede señalar, que no es necesario tener en cuenta la coexistencia de diversos talentos, sino la complejidad y la extensión del talento en la persona, para con su entorno. El hecho de que un individuo pueda exteriorizar diferentes talentos, solo dependerá de la misma persona, de qué tan versátil pueda llegar a ser en cuanto a sus propios límites. La oportunidad dada de poder complementarse como un sujeto que domina distintos talentos, es de gran valor social, podría esto impactar positivamente su vida personal y profesional, pero lo realmente importante será la actitud con la que asuma el ser humano esta posibilidad que recibe.

Cuando se dialoga de todo el ser se expresa en el talento, se parte de la idea de que el cuerpo es el mayor medio que se tiene para expresarse, desde la cabeza a los pies estamos cubiertos por una capa de terminaciones ligadas al sistema nervioso central, el cual alimenta cada una de las acciones, sentimientos, emociones, pensamientos y comportamientos que expresamos en un determinado momento. De este modo, el cuerpo se convierte en un instrumento irremplazable de expresión humana, que permite ponerse en contacto con el medio y con los demás.

El talento demostrado por una persona requiere de un conjunto de elementos físicos que le permitan exteriorizar lo que se encuentra en su interior, y es a través del cuerpo que se puede experimentar cada sensación que genera el mostrar las habilidades que se tienen cuando una circunstancia lo amerite. Al hacer uso del talento, el cuerpo se convierte en el principal recurso que se tiene para revelar lo que se desea y es allí donde Armstrong (2017), señala que el cuerpo en toda su extensión permite expresar ideas y sentimientos, al igual que podemos a través de él crear o transformar. 
Los párrafos anteriores sobre talento: una esencia individual, develan que el o los talentos de cada persona le distinguen en un contexto determinado, les genera satisfacción y da oportunidades para enriquecer el desarrollo personal y profesional del individuo, deja la idea poderosa de que el talento refleja quién soy. Ver el talento lejos de las concepciones tradicionales que hasta hoy se han creído es un gran paso que permite concebir al individuo como una unidad integral, en la que convergen aspectos intrínsecos y extrínsecos que le forman. Se hace referencia a que todas las personas son poseedoras de potencialidades que juegan un papel en cada vida, por lo que reflejan quienes somos y que tan lejos podemos llegar.

Seguidamente, se presenta una representación mental que lleva a la reflexión de los pensamientos descubiertos e interpretados en este apartado.

\section{¿De Dónde Vienen los Talentos?}

Talento, es un término que engloba diferentes aspectos propios del ser humano, considera las cualidades de cada persona, esas características o rasgos que de modo ontológico deja ver la realidad de éste, lo que le individualiza del resto de sus similares, lo configura como ser único. Para el Diccionario de la Real Academia Española (RAE) (2021), en la primera y tercera acepción, muestra que una cualidad da un carácter distintivo, de calidad sobre la naturaleza de alguien o algo y se expresa normalmente a través de adjetivos.

Lo anterior expone que una cualidad será un aspecto que describe a un individuo o cosa, esto lleva a que se puede concebir la inherencia como una propiedad que asume el talento de un sujeto. Si se parte de lo dicho por la RAE (2021), cuando señala el carácter distintivo de algo, se percibe al talento como el atributo que se manifiesta en alguien y es exteriorizado por el mismo. Según el citado diccionario, el concepto inherente hace referencia a todo aquello que naturalmente está unido y es inseparable de otra.

Revisados ambos términos: cualidad e inherente, al vincularlo al tema de investigación, se interpreta que toda persona porta unas potencialidades que se entienden como la cualidad que éste demuestra y que está ligada al sujeto de forma propia, por lo que siempre ha estado y estará presente cuando el individuo vive su cotidianidad.

Esta idea planteada deja atrás las creencias tradicionales sobre el talento, como las concepciones desde la inteligencia, posición netamente innatista y posturas del 
superdotado; se evoluciona y surge entonces, una nueva opinión que define que toda persona tiene talento, por lo tanto, se darán de manera innata o adquiridos, simplemente hay que darle el espacio para que aflore.

Entendida la idea de este apartado, se indaga sobre aspectos diversos que dan referencia a ¿De dónde vienen los talentos? Posterior a la revisión detallada de variados estudiosos, procedo a la creación de un cuadro que categoriza algunos puntos que luego serán expuestos a la luz de las investigaciones revisadas. Entre los aspectos descubiertos están: del ser mismo, carácter innato: impreso en la naturaleza de cada quien o del conjunto social, carácter social: es aprehendido en la vida, de la cognición: unido a la inteligencia y capacidad de aprender, y, finalmente, de Dios: carácter metafísico; tal como se observa en el siguiente cuadro 2 :

\section{Cuadro 2. ¿De dónde vienen los talentos?}

\begin{tabular}{ll}
\hline \multicolumn{3}{c}{ Aspecto descubierto } & \multicolumn{1}{c}{ Idea poderosa } \\
\hline $\begin{array}{l}\text { - Del ser mismo, carácter innato: } \\
\text { impreso en la naturaleza de cada quien } \\
\text { o del conjunto social, carácter social: } \\
\text { es aprehendido en la vida }\end{array}$ & $\begin{array}{l}\text { El talento está presente en la persona desde su } \\
\text { nacimiento y durante su vida se desarrolla, nunca deja de } \\
\text { ser, aun cuando no se practique. También puede ser } \\
\text { aprehendido durante la existencia del individuo. }\end{array}$ \\
$\begin{array}{l}\text { - De la cognición: unido a la } \\
\text { inteligencia y capacidad de aprender }\end{array}$ & $\begin{array}{l}\text { Contempla el criterio de que el talento puede ser } \\
\text { aprendido desde la interacción con los entornos que } \\
\text { enriquecen a un individuo. Este puede ser develado } \\
\text { luego de tener la oportunidad de participar en una } \\
\text { vivencia que deje interés por adentrarse en el } \\
\text { conocimiento de dicha potencialidad. } \\
\text { Aporta la idea del talento como un don otorgado por } \\
\text { Dios. Estos dones concedidos son intransferibles le } \\
\text { pertenecen solo a la persona. }\end{array}$ \\
\hline
\end{tabular}

Fuente: Propia

Al revisar documentos relacionados con el origen de las aptitudes en el ser humano, se encuentran varias ideas que le exponen, una de ella es: Del ser mismo, carácter innato (impreso en la naturaleza de cada quien o del conjunto social), carácter social (es aprehendido en la vida). Es interesante leer escritos que señalan que el talento se manifiesta desde que se nace, y si se deja de ejecutar por un tiempo nunca se olvida, al retomarlo, se vuelve a ser tan bueno como antes, por lo que al pasar de los años se desarrolla y se pule, esto permite interpretar que el talento da al individuo la oportunidad de demostrar sus 
habilidades, con las cuales han nacido, pero al interactuar con los diferentes contextos en los que hacen vida, pueden llegar a vivir una especie de transformación que les lleva a alcanzar un mayor desarrollo de sus talentos, se verán estos mejorados al momento de hacer uso de ellos.

En este sentido, Torcomian y Sánchez (2017), apuntan que el talento refiere a una facilidad natural que posee una persona para realizar determinada actividad. También, creen que "El talento innato...requiere ser ejercitado sistemáticamente para no perderse, no obstante, ésta habilidad estaría en germen en el interior del sujeto" (p.3). Allí se ve con claridad que el talento habita en los individuos y necesita de la práctica diaria para mantenerlo activo, pero esto solo será una decisión ineludible de cada sujeto. Visualizar lo planteado por los precitados autores, permite la visualización de un talento que está presente en el ser humano desde su nacimiento pero que en sus manos está el hecho de mantenerlo activo o dejarlo almacenado, hasta que decida hacer uso del mismo.

El talento se convierte en un aspecto de la vida de una persona que como se ha dicho en párrafos anteriores, le hace destacarse en lo que hace, pero consciente siempre de que, para poder mantener una buena actitud que se destaque, se debe estar en constante proceso de actualización, con la firmeza de ser mejores cada día en lo que sabemos ejecutar.

Cada uno de nosotros hemos nacido con diferentes habilidades y poco a poco se aprenden cosas nuevas que nos hacen ser mejores en lo que hacemos, se produce un desarrollo del talento, en este proceso se incorporan nuevos aprendizajes que nutren a la persona y por ende al talento que se materializa en ella. Gagné (2009), considera que la prosperidad del talento se da de forma progresiva, con la intención de lograr un auge completo en la persona, pueda esta interactuar con su entorno de manera armoniosa y consiente de que su talento está al beneficio de otros y en el suyo propio.

Finalmente, se puede ver que la inherencia del talento como cualidad en el ser humano, está marcada por el desarrollo de las habilidades que se encuentran en la persona desde su niñez, pero que requieren de conciencia individual para mantenerse activo en lo que hace y si fuera el caso en el cual, se dejara de ejercitar por un tiempo, estas potencialidades siempre están prestas a ser retomadas para volver a formar parte del día a día de un sujeto, con las cuales puede llegar a impactar a su entorno más inmediato. 
Otro aspecto a revisar en cuanto al origen del talento es el vinculado a la cognición: unido a la inteligencia y capacidad de aprender, se expone el hecho que, durante la revisión de la inherencia del talento, aparecen documentales que complementan la idea de que el talento puede ser aprendido desde la interacción con los entornos que enriquecen a un individuo. Diversos estudiosos se han dedicado a profundizar en la vinculación que existe entre el ambiente social y el desenvolvimiento de las personas en ciertos momentos. Al hablar de interacción se consideran elementos propios de los contextos en los cuales se llevan a cabo las experiencias y los sujetos que se relacionan, de los cuales surgen oportunidades que conllevan al crecimiento de esta. Los entornos sociales constituyen un universo de experiencias, significaciones que impulsan al auge de los individuos y la evolución de su progreso en todos los aspectos de su vida (Rogers, 2011).

Este florecimiento al que se hace mención, se da en gran parte por las oportunidades que vivencia el ser humano en diferentes contextos en los que lleva su día a día. Al indagar uno a uno cada estudio acerca a este punto se aprecian una serie de conductas que aparecen en la medida en que los sujetos viven ciertas experiencias que le llevan a reevaluarse. Todo esto, les permite descubrir potencialidades que al ser ejercitadas constantemente se visualizan como talentos que emergen de la cotidianidad de cada una.

En este momento se aporta un ejemplo que sirve para ilustrar lo planteado: una persona toca un instrumento, el cuatro, lo descubrió durante sus estudios universitarios, realiza cursos para aprender un poco más. Al revisar ella su libreta se da cuenta que fue en el año 2015 que aprendió este talento, recuerda que todo empezó con un curso académico, a pesar de su edad en ese momento, identifica que aprendió algo nuevo, nunca es tarde, actualmente ayuda a otros a descubrir sus potencialidades. Claramente se lee que el talento de esta persona lo descubre en el transcurso de su formación pedagógica, ya en edad joven y nunca antes lo había practicado.

Luego de esta experiencia inicial, se despierta el interés en ella por continuar en el aprendizaje en relación a su nuevo talento (musical), se inscribe en talleres y se incorpora a grupos de músicos, con los cuales vive experiencias que enriquecen el desarrollo de su talento, hasta el punto, de ahora ser ella quién prepara a otros en la incursión de tocar el cuatro a nivel profesional. Para Betancourt y Valadez (2003), "El talento sólo puede desarrollarse por medio del intercambio favorable entre los factores individuales y sociales” 
(p. 39). Estos escritores plantean que el talento se forma y se adquiere en la actividad misma, es decir, la experiencia de vivirla. No se puede creer tener un talento sino lo has experimentado.

Las líneas que preceden denotan que el talento puede ser develado luego de tener la oportunidad de participar en una vivencia que deje interés por adentrarse en el conocimiento de dicha potencialidad. Esta naciente aptitud se vislumbra con la interacción en distintos contextos y en la medida que crece en la individualidad, se puede buscar acompañamiento de otros que ya conocen más su talento para que florezca el reciente hasta que impacte en el desarrollo personal y profesional del individuo. El talento no es simplemente un don grabado en los genes de una persona, este puede desarrollarse si se tienen experiencias que despiertan interés en algo, se practican dichas habilidades y se busca la ayuda de otros más avanzados en esta área, para así asirse del talento como un aspecto de tu vida (Coyle, 2009).

Los talentos pueden ponerse al descubierto y desarrollarse con los medios idóneos, palabras de Alles (2006), que dan fuerza a las ideas planteadas en estos párrafos, en los cuales se tiene claro que el o los talentos pueden ser revelados desde las experiencias de vida, en la medida que se ejercitan con las personas y medios necesarios, para llegar a formar una columna importante en la vida de un individuo.

Otro punto encontrado en torno a ¿De dónde vienen los talentos?, está lo relacionado con los escritos que hacen mención a su origen desde Dios, con un carácter metafísico, que aporta la idea del talento como un don otorgado por Dios. Maswell (2007) expresa que es un obsequio celestial, que debe ser cuidado, buen empleado y desarrollado. Incluso la biblia dedica algún escrito en relación al talento que es entregado a las personas y cómo este se multiplica en la medida que se trabaja de forma intencional.

Hablar de talento como un regalo divino, denota una gran fortuna para quien lo posea. En este sentido la versión Reina Valera de la Biblia (1960), en el libro de Mateos 25: 14 al 30 dedica varias líneas en las que se percibe que a cada persona Dios le entrega una dote, que según sea la decisión que tome, trabajará para aumentarla o dejará que el tiempo pase, sin ni siquiera darse cuenta del valor real que tiene lo que se le ha provisto. También, se puede evidenciar en el escrito bíblico, que reparte de forma diferente a los individuos, y tendrán medida distinta con respecto a otros. 
Lo escrito anteriormente, muestra que Dios designa a cada sujeto talentos que pueden ser empleados en el trascurrir de vida, queda en la decisión de las personas como honrará el regalo que le ha sido entregado. Estos dones concedidos son intransferibles le pertenecen solo a él o ella, este es inalienable, a cada quien le toca el suyo en cuanto a las potencialidades, pero como persona conservan su misma valoración, nadie es más que nadie. Maxwell (2007), plantea que "Las personas tienen el mismo valor, pero no la misma habilidad" (p.7).

Así como Dios ha premiado a cada ser humano con talentos extraordinarios, sin hacer distinción entre ellos, también permite que las aptitudes que posee un sujeto sean ampliadas hasta alcanzar nuevos talentos a partir del que ya se posee, Dios tiene la potestad de dar a cada uno según su voluntad, planteamientos emergentes que permiten interpretar la existencia de una cosmovisión relacionada con el pensamiento cristiano. A esta potestad divina se agrega la interpretación de que está en manos de la humanidad qué hacer con cada una de las potencialidades que le han sido entregadas.

Finalmente, al escudriñar los diversos contenidos surge la premisa de que el talento es una cualidad que se encuentra en los individuos y se destaca por su inherencia en el mismo, lo que enfatiza la idea de que todos somos seres talentosos desde el nacimiento, de modo aprendido o por la voluntad de Dios, en cualquiera de los casos, solo se requiere de una decisión personal para permitir que la potencialidad florezca y se convierta en una fuerza que impulsa el desarrollo del sujeto. Cada persona que conozco es talentosa en algo. En ocasiones los talentos son evidentes a todos, en otros se encuentran escondidos, Pero los talentos están ahí. Seguidamente, se expone una representación que lleva a la reflexión de lo tratado en estos párrafos.

\section{Reflexiones Finales de una Realidad}

Luego de revisado, leído e interpretado cada documento seleccionado para el estudio, parto de la frase "El saber constituye un sentimiento que se vive cuando imaginamos, y el producto de lo imaginario rompe los límites de lo que sabemos" (p. 81), palabras del escritor Ugas (2013), que interpreto desde el sentimiento vivido de imaginar algo y ver que el fruto concretado sobrepasa lo ideado rompe los límites, pero que aún permite más a la imaginación, nacen otros pensamientos, emociones, realidades expresadas en las palabras, 
las acciones, las voces, los escritos... En esta profusión, mi talento, que es talento que todos pueden leer, que ha roto los linderos de lo que creía y ha sobrepasado lo imaginario.

En el extenso de este documento científico, ha quedado clara la idea de que el talento es una cualidad inherente al ser humano, que se descubre y desarrolla según la decisión de cada persona, estas aptitudes hacen presencia en cada uno de los individuos, sin importar condición social, preparación académica, edad, credo o nacionalidad. La idea plasmada se aleja de lo dicho por distintos estudiosos en el área, que han preconcebido al talento como una condición que solo algunos pueden expresar y que dependerá en gran medida del status mental o de las condiciones sociales que impulsan sus manifestaciones.

En el presente ensayo se cree en un talento que se exterioriza en cualquier área del desenvolvimiento humano, sea profesionalmente demostrable o como un oficio que sirve de apoyo a la persona y a su contexto inmediato. No solo será ese sujeto que marcadamente se comporta sobresaliente en un área y que hasta es clasificado como una población superdotada por sus características ampliamente notables. Aquí se cree en las habilidades que desde niño puedes poseer o las que en la adultez son descubiertas, desarrolladas y llevadas a la práctica cotidiana para hacer de ella una herramienta que combina el ser, con el hacer.

Finalmente, con cada documento revisado se llega a entender “...que realizar una investigación no solo es enunciar conceptos, es tener un pensamiento que piensa cuando se reflexiona lo que se dice, para inferir lo que se calla" (p. 62) (Ugas, 2013). Al mismo tiempo que se entiende lo real que es lo dicho por Tom Paterson (citado por Fields \& Rees, 2008) "Muéstrame una persona que no conozca sus talentos o que no los haya desarrollado para servir a otros, y te mostraré una persona que tiene poco sentido de propósito, de significado, de motivación y de valor" (p. 22).

Es interesante comprender que, al develar públicamente este artículo, se deja la puerta abierta para iniciar nuevos caminos, con ideas que se acercan a reflexiones más amplias en relación al talento, con las cuales se permite adentrarse al mundo interno de las personas desde sus talentos, para así profundizar en las distintas realidades que emergen desde las palabras de los propios actores.

\section{Referencias}


Alles, M. (2006). Desarrollo del talento humano: basado en competencias. Granica S.A. https://books.google.es/books?hl=es\&lr=\&id=FYxjjgmxVaIC\&oi=fnd\&pg=PA11\& $\mathrm{dq}=$ todos+los+seres+humanos+tenemos+talentos\&ots=wk7KKk2gpm\&sig=OsNEs tT6LN9vov5iAE6cKKiLKhA\#v=onepage \&q\&f=true

Andreucci, P. (2016). Talento y Argumentación: Una Alianza Dialógica en el Aula. Profesorado. Revista de currículum y formación del profesorado, 20 (2), 2-17. https://www.redalyc.org/pdf/567/56746946001.pdf

Armstrong, T. (2017). Inteligencias múltiples en el aula. Editorial Paidos Educación. https://www.planetadelibros.com/libros_contenido_extra/37/36195_INTELIGENCI AS_MULTIPLES_AULA.pdf

Betancourt, J. y Valadez, M. (2012). Cómo propiciar el talento y la creatividad en la escuela. Editorial Manual Moderno

Cabrera, P. (2011). ¿Qué debe saber y saber hacer un profesor de estudiantes con talento académico? Una propuesta de estándares de formación inicial en educación de talentos. Revista Estudios Pedagógicos, $37 \quad$ (2), 43-59. https://scielo.conicyt.cl/pdf/estped/v37n2/art02.pdf

Capo, J. (1986). Psicología humanista y educación [Monografía]. https://scholar.googleusercontent.com/scholar?q=cache:S6jH6VFA910J:scholar.goo gle.com/+humanismo+de+carl+rogers\&hl=es\&as_sdt=0,5

Coyle, D. (2009). Las claves del talento ¿Quién dijo que el talento es innato? Aprende a desarrollarlo. Effective Management S.L. http://conectatutalento.com/wpcontent/uploads/2014/10/1.-Las-claves-del-talento.Dan-Coyle.pdf

Fields D. y Rees E. (2008). Descubriendo tus talentos para dejar una marca en el mundo. Editorial

Vida. https://books.google.co.ve/books?id=2wHsKsHVJ6wC\&pg=PT58\&dq=que+es+talentos\&h $1=e s \& s a=X \& v e d=0 a h U K E w j z-$ 8qn95fnAhWJtlkKHVB_Cl4Q6AEILTAB\#v=onepage \&q=que $\% 20 \mathrm{es} \% 20$ talentos $\& \mathrm{f}=$ false

Gagné, F. (2009). Construyendo talento a partir de la dotación [Monografía]. http://www.eurotalent.org/Gagne_MDDT_Modelo.pdf

García, S. (2016). Aprovechando los talentos y fortalezas de cada alumno para desarrollar $s u$ potencial [Monografía]. http://e- 
spacio.uned.es/fez/eserv/bibliuned:masterComEdred-

Sariza/Ariza_Garcia_Susana_TFM.pdf

Gardner, H, (2001), Estructuras de la mente, la teoría de las inteligencias múltiples. Fondo de Cultura Económica. http://biblioteca.udgvirtual.udg.mx:8080/jspui/bitstream/123456789/593/1/Estructur a\%20de\%201a\%20mente.\%20teoria\%20de\%201as\%20Inteligencias\%20multiples.p df

Hernández, C. (8 de marzo de 2018). Fabricar profesionales desarrollo del talento. http://identidadorganizacional.com/2018/noticias/fabricar-profesionales-desarrollodel-talento/

Lorenzo, R. (2006). ¿A qué se le denomina Talento?. Estado del arte acerca de su conceptualización. Revista Intangible capital, $2 \quad$ (11), 72-173 https://upcommons.upc.edu/revistes/bitstream/2099/2933/1/A\%20que\%20se\%20le $\% 20$ denomina\%20talento.pdf

Malavassi-Calvo, F. (2017). Ensayo acerca del Enfoque o Filosofía Humanista relativa a la Educación. Revista Uaca, 33-50. http://revista.uaca.ac.cr/index.php/actas/article/view/73/42

Maxwell, J. (2007). El talento nunca es suficiente. Grupo Nelson, Inc.

Ministerio de Educación, Cultura y Deporte. (1997, Diciembre). Conceptualización y Política para el Desarrollo del Talento. Caracas: Autor.

Montaño, M., Palacios, J, y Gantiva, C. (2009). Teorías de la personalidad. Un análisis histórico del concepto y su medición. Revista Psychologia. Avances de la disciplina, 3 (2), 81-107. https://www.redalyc.org/pdf/2972/297225531007.pdf

Osorio, B. (2000). Discapacidades Asociadas. UPEL-IMPM

Real Academia Española (2021). Cualidad - Habilidad. Diccionario de la Lengua Española. Recuperado el 5 de febrero de 2021, de https://www.rae.es/

Regader, B (20 de agosto de 2015). La teoría de las inteligencias múltiples de Gardner. https://psicologiaymente.com/inteligencia/teoria-inteligencias-multiples-gardner

Rodríguez, L., Aguiar, X. y Santos, E. (2019). Estimular el desarrollo de alumnos talentos en las condiciones actuales de la educación superior. Revista Edumecentro, 11 (1), 
160-183 https://dspace.uclv.edu.cu/bitstream/handle/123456789/11110/1283-59672-PB.pdf? sequence $=1 \&$ is Allowed $=\mathrm{y}$

Rogers, C. (2011). El proceso de convertirse en persona. Editorial Paidós. https://books.google.co.ve/books?id=8Mh0AgAAQBAJ\&printsec=frontcover\&hl=e $\mathrm{s} \# \mathrm{v}=$ onepage $\& \mathrm{q} \& \mathrm{f}=$ true

Salazar, T. y Fernández, C. (2016). Las potencialidades talentosas en los niños de la educación preescolar. Revista Varona, $62 \quad$ (1), 1-9. https://www.redalyc.org/pdf/3606/360657458013.pdf

Santa Biblia (1960). Biblia devocional de estudio. La Liga Bíblica

Teplov, BM. (1961). Problemas de las diferencias individuales. Academia Rsfsr de ciencias pedagógicas

Torcomian, C. y Sánchez, A. (2017). Creencia sobre talento y aprendizaje en estudiantes de música [Resumen de presentación de la conferencia]. IX Congreso Internacional de Investigación y Práctica Profesional en Psicología XXIV Jornadas de Investigación XIII Encuentro de Investigadores en Psicología del MERCOSUR. Facultad de Psicología, Buenos Aires. https://www.aacademica.org/000067/543.pdf

Ugas, G. (2013). Del acto de conocer al discurso que lo narra: Una problemática epistemológica. Lito-Formas

Velasco, -- y Prieto, -- (23 de diciembre de 2012). El talento directivo. https://www.unniun.com/el-talento-directivo/

Vinueza, T. y Castro, J. (2018). Desarrollo del Talento en la educación formal. Revista electrónica de investigación y docencia, $20 \quad$ (79), 73-90. https://revistaselectronicas.ujaen.es/index.php/reid/article/view/3579/3251

Zavala, M. y Rodríguez, J. (2004). El campo educativo de niños y jóvenes con aptitudes sobresaliente. Relieves históricos y problemática actual. Revista Educar, 29 (1), 3544 http://quadernsdigitals.net/datos_web/hemeroteca/r_24/nr_648/a_8731/8731.pdf 